\title{
Erratum to: Characterization of a novel flooding stress-responsive alcohol dehydrogenase expressed in soybean roots
}

\author{
Setsuko Komatsu • Thibaut Deschamps · Susumu Hiraga • \\ Mikio Kato • Mitsuru Chiba • Akiko Hashiguchi • \\ Makoto Tougou $\cdot$ Satoshi Shimamura $\cdot$ Hiroshi Yasue
}

Published online: 25 November 2011

(C) Springer Science+Business Media B.V. 2011

Erratum to: Plant Mol Biol (2011) 77:309-322

DOI 10.1007/s11103-011-9812-y

Due to an unfortunate turn of events, the first- and surname of the second author were interchanged. The correct representation of the authors and their affiliations are listed above and below and should be treated as definitive by the reader.

The online version of the original article can be found under doi:10.1007/s11103-011-9812-y.

S. Komatsu ( () - T. Deschamps · S. Hiraga · A. Hashiguchi ·

M. Tougou - S. Shimamura

National Institute of Crop Science, Kannondai 2-1-18,

Tsukuba 305-8518, Japan

e-mail: skomatsu@affrc.go.jp

T. Deschamps

University Pierre et Marie Curie University, 75005 Paris, France

M. Kato

Osaka Prefecture University, Osaka 599-8531, Japan

M. Chiba $\cdot$ H. Yasue

National Institute of Agrobiological Sciences,

Tsukuba 305-8602, Japan

M. Chiba

University of Tsukuba, Tsukuba 305-8577, Japan 